\title{
Coercion in mandated community treatment: its relativity and effects
}

\author{
Virginia Aldige Hiday
}

\author{
Address: North Carolina State University, Box 8107, Raleigh, North Carolina 27695, USA \\ from WPA Thematic Conference. Coercive Treatment in Psychiatry: A Comprehensive Review \\ Dresden, Germany. 6-8 June 2007 \\ Published: 19 December 2007 \\ BMC Psychiatry 2007, 7(Suppl I):SI26 doi:I0.II86/I47I-244X-7-SI-SI 26
}

This abstract is available from: http://www.biomedcentral.com/I47I-244X/7/SI/SI 26

(C) 2007 Hiday; licensee BioMed Central Ltd.

\section{Background}

The weight of the evidence on mandated outpatient treatment indicates that it is effective in reducing victimization, violence, arrests, and hospitalization. Some of the empirical evidence points to increased compliance with treatment and reduced substance abuse as the mechanisms through which it works; but we do not know how the coercion felt under OPC operates to influence these two mechanisms.

\section{Methods}

We review attempts to measure patient perceptions of coercion in mandated community treatment quantitatively and examine their findings in relation to measures of coercion in other mental health treatment modalities and to measures of coercion from other sources.

\section{Results}

Patient perceptions of coercion in mandated community treatment range from low to high levels but tend to fall near the low end of the scale and are significantly lower than perceptions of coercion in involuntary hospitalization. Patient views of coercion are relative to other pressures in their lives and do not determine satisfaction or outcome.

\section{Conclusion}

Patients are ambivalent in their views of mandated outpatient treatment. How it works with procedural justice and other formal and informal elements of mandated community treatment to produce compliance with medication and reduced substance abuse is unclear. 